\title{
12
}

\section{Assessing Wellbeing in School Communities}

\author{
Aaron Jarden, Rebecca Jarden, Tan-Chyuan Chin, \\ and Margaret L. Kern
}

Imagine that a group of students joins your school, and you have no records of their abilities or past performance. How do you determine which year level they should be a part of and what their learning needs might be? You would likely use a variety of tools to assess the level that the students are at, and to match them with other students who are at a similar learning level. Likewise, the same principle applies for the assessment of individuals within a school community regarding their psychological wellbeing, and for the usefulness of such data for making decisions. Moreover, assessment of a school community's psychological wellbeing is a crucial link in the positive education chain-not only to determine where the community's wellbeing is at one point in time, but also to inform possible intervention approaches both initially and going forward, with targeted adaption over time. Without this vital information about what aspects are working for whom, and which aspects are driving, increasing, or compromising wellbeing, practitioners and education decision-makers are largely flying blind and not aptly applying practices which are theoretically grounded or research based.

\footnotetext{
A. Jarden $(\bowtie) \cdot$ T.-C. Chin $\cdot$ M. L. Kern

Centre for Wellbeing Science, Melbourne Graduate School of Education, University of Melbourne, Melbourne, VIC, Australia e-mail: aaron.jarden@unimelb.edu.au

R. Jarden

Department of Nursing, Melbourne School of Health Sciences, University of Melbourne, Melbourne, VIC, Australia
} 
As such, wellbeing assessments are critical in the context of positive education initiatives.

In this chapter, we firstly summarize the basics of assessment and principles of good assessment. Secondly, we outline wellbeing assessments in schools: what they are, why they are important, and examples of good assessment tools and their use in practice. Thirdly, we illustrate how wellbeing assessment data can be used in decision-making for various stakeholders. Finally, we provide a comprehensive list of questions schools and decision-makers may find useful in considering assessment tools and approaches. It is our hope that this chapter will aid in encouraging appropriate wellbeing assessments in schools, especially aligned with positive education initiatives, and make initiatives more useful in establishing and sustaining positive education in school communities.

\section{Assessment Basics}

\section{What Is Assessment?}

There are four key related terms that need to be clarified: testing, measurement, assessment, and evaluation. From a psychometric perspective, testing can be defined as "the act or practice of giving tests to measure someone's knowledge or ability" (Cambridge English Dictionary, 2019c), with a test being "an instrument or technique that measures someone's knowledge of something to determine what he or she knows or has learned" (Penn State University, 2019, First section, para 1). For example, testing might involve administering a reading level test to a child. Measurement refers to when "a 'test' is given, and a 'score' is obtained" (Shum, O'Gorman, Myors, \& Creed, 2013, p. 17). For example, measurement would reflect the child's result (the score) of the reading test. Assessment refers to "the act of judging or deciding the amount, value, quality, or importance of something, or the judgment or decision that is made" (Cambridge English Dictionary, 2019a). From an education perspective, assessment can be defined as "the wide variety of methods or tools that educators use to evaluate, test, measure, and document the academic readiness, learning progress, skill acquisition, or educational needs of students" (Glossary of Education Reform, 2015). For example, the reading test that was administered to the child is used to assess the child's reading level. Lastly, evaluation can be defined as "the process of judging or calculating the quality, importance, amount, or value of something" (Cambridge English Dictionary, 2019b), but can also be conceived as 
the process of determining the worth or value of the result of a measurement (Shum et al., 2013). For example, the child's reading level is used to decide their placement in a particular class level.

Clearly there is a lot of overlap amongst these definitions, and one may begin to wonder what the difference is amongst testing, measurement, assessment, and evaluation. Rather than trying to distinguish these lexicologically, we address these from a practical perspective. We consider that a test provides a measurement of some aspect, or aspects, of which can then be evaluated against some criteria or knowledge base. This process as a whole can be conceived of as encompassing the process of assessment more broadly. That is, assessment can be considered the broader process, which incorporates tests, measures, and evaluations. Specifically, an assessment involves a test of some sort, which measures some aspects and collects data, and then an evaluation is made of the data.

\section{Principles of Good Assessment}

Knowing what assessments are, it then follows that there are some principles which allow for good assessments. Here we highlight three principles that we believe are important for good assessments in school communities.

Firstly, assessments should follow appropriate psychological assessment processes (see for instance Shum et al., 2013). The process begins with careful planning of the assessment (e.g., identifying the goals of assessment and the best approaches to meet those goals). This is followed by data collection, which obtains quantitative and/or qualitative information through approaches such as surveys, observations, behavioural measures, existing records, or experience sampling. Next, data need to be processed. This might involve coding and processing the raw data, statistical analyses appropriate to the goals of the assessment, and judgements about what the data show. Finally, results are communicated through a variety of means (e.g., written reports, verbal reporting, infographics, conference presentations, academic papers, direct communication to participants and other stakeholders). A good assessment should follow these four main overarching processes.

Secondly, assessment should be psychometrically sound. By this we mean that the measures, as a whole and not in part, should be rigorously tested and empirically validated, with careful attention to their validity and reliability. Validity ensures that the assessment effectively measures what it both purports to and should measure. Reliability requires that the assessment can be relied upon to provide consistently accurate results. A good assessment should be both valid and reliable (See Chapters 4 and 5 of Shum et al., 2013; Cook \& 
Beckman, 2006; Coolican, 2014, for detailed discussion and consideration of validity and reliability.)

Thirdly, assessments should follow appropriate ethical approaches (Jarden, Rashid, Roache, \& Lomas, 2019). An ethical approach is a broad category that could include aspects such as: always checking and obtaining copyright for psychometric test usage, using appropriate tests for the ages and contexts, only collecting information that there is a plan to use, obtaining appropriate consent, considering issues of privacy and confidentiality, safe data storage, and considering the dangers in some types of testing feedback such as to very young children or around sensitive topics (see Kern et al., 2020 for ethical aspects to consider with school-based assessments that include wellbeing and mental health information). Good assessments take into account these different ethical aspects, striving to avoid harm (non-maleficence) and to do what is good and right (beneficence).

\section{Wellbeing Assessment}

With this background on what assessments refer to and principles of good assessment, we turn specifically to wellbeing assessments within school communities. A wellbeing assessment is an assessment that focuses on psychological wellbeing - broadly defined. Thus, it firstly depends on the definition of wellbeing that one adopts, and secondly on the model of wellbeing that this definition is aligned to. We first consider definitions and models that have been used within positive education, and then point to context and process aspects. In addition, particularly relevant to assessment within school communities, we highlight the importance of considering the system within which assessments occur.

\section{Defining Wellbeing}

Common definitions of wellbeing focus on the individual, such as: "wellbeing can be understood as how people feel and how they function both on a personal and social level, and how they evaluate their lives as a whole" (Michaelson, Mahony, \& Schifferes, 2012, p. 6.), and "the notion of how well a person's life is going for that person. A person's well-being is what is 'good for' them" (Crisp, 2017, The Concept section, para 1). ${ }^{1}$

\footnotetext{
${ }^{1}$ See Oades and Heazlewood (2017) for a nuanced consideration of wellbeing definitions.
} 
In line with the original conception of positive psychology (Seligman $\&$ Csikszentmihalyi, 2000), we agree and contend that wellbeing not only incorporates aspects of what is going well in life (having happiness, a sense of meaning, engagement, etc.), but also incorporates aspects of ill-being (having depressed mood, loneliness, feelings of stress, etc.), thus encompassing a broad spectrum or continuum. Therefore, a wellbeing assessment ought to capture both what is going well and what is not going well for an individual. It also includes multiple domains, such as emotions (e.g., happiness, sadness), cognitions (e.g., judgements about one's life satisfaction, trouble concentrating), behaviours (e.g., practising gratitude, crying), and physiology (e.g., heart rate variability, somatic symptoms).

There are a host of additional issues and distinctions that could be discussed with regard to wellbeing definitions, such as lay versus expert definitions, hedonic versus eudaimonic conceptions, subjective versus objective perspectives, unidimensional versus bidimensional conceptions, and experienced versus evaluative notions (see for instance Diener, 2009; Organisation for Economic Co-operation and Development [OECD], 2013 for consideration of these issues). There is no internationally agreed-upon definition of wellbeing that currently exists, other than that it is multi-faceted (Hone, Jarden, Schofield, \& Duncan, 2014). Furthermore, and sometimes confusingly, the term "wellbeing" is quite often used interchangeably with the terms "mental health", "mental illness", "wellness", "quality of life", "happiness", "thriving", "flourishing", and "health", amongst others (Hone, Jarden, \& Schofield, 2014). These issues all compound and are layered challenges as the lack of a definition of "wellbeing" makes deciding which model to base a wellbeing strategy upon, and which psychometric tool or tools to select for assessments, a conundrum for practitioners, and decision-makers.

\section{Models of Wellbeing}

There are many wellbeing models in the education space, and a full review is beyond our scope here (see Positive Education Schools Association [PESA], 2020 for a more nuanced discussion of existing wellbeing frameworks and identification of other models used within education). To illustrate, we outline four models that, from our experience, have commonly been incorporated as guiding frameworks for positive education within Australian schools.

First, Seligman's PERMA (2011) model has become popular over the past decade. Seligman contends that wellbeing arises from nurturing five elements: Positive emotion, Engagement, Relationships, Meaning, and Accomplishment. Many schools adapt the model to capture additional dimensions. For 
example, Geelong Grammar School in Victoria, Australia includes $\mathrm{H}$ for health is added (i.e., PERMAH), with all elements infused with the notion of character strengths (Norrish, 2015). The Wellbeing and Resilience Centre in South Australia uses PERMA+, where the "+" refers to the four elements of optimism, nutrition, sleep, and physical activity (Iasiello, Bartholomaeus, Jarden, \& Kelly, 2017).

Second, Water's Visible Wellbeing TM (Waters, 2017; Waters, Sun, Rusk, Aarch, \& Cotton, 2017) is an approach that aims to combine the science of wellbeing with the science of learning to build wellbeing via teacher pedagogy using the SEARCH framework (Strengths, Emotional management, Attention and awareness, Relationships, Coping, and Habits and goals: Waters, 2018; Waters \& Loton, 2019). The SEARCH framework is based on Rusk and Waters' (2015) Five Domains of Positive Functioning, which specially focuses on psychosocial functioning, defined to mean "the moment-bymoment psychological and social processes, states and events that contribute to well-being" (p. 141). As Visible Wellbeing is a pedagogical approach, it broadens positive education beyond program delivery.

Third, Five Ways to Wellbeing was developed by the New Economics Foundation (NEF) in the U.K. (Aked \& Thompson, 2011), but has spread internationally. The New Economics Foundation was commissioned by the U.K. government to develop a set of evidence-based actions to improve personal wellbeing. Using accessible language and building on an extensive review of the wellbeing literature (i.e., the Foresight Mental Capital and Wellbeing Project), NEF identified five ways for supporting wellbeing: Connect, Be active, Take notice, Keep learning, and Give.

Fourth, Noble and McGrath (2015) proposed the PROSPER framework, which focuses on seven components: Positivity, Relationships, Outcomes, Strengths, Purpose and meaning, Engagement, and Resilience. The framework aims to provide an organizational tool for the implementation of the seven components to help people, groups, organizations, or communities to flourish or function optimally. The authors suggest it can be used as a planning tool or as an audit tool to help schools to identify current areas of strength and practices that might need to be further enhanced.

These four frameworks give just a taste of the many models and frameworks that are available. Some schools choose to use these models to guide measurement and practice; other schools have developed their own frameworks or variants of these models to fit the values and context of their school. Regardless of the model chosen, it is important that there is alignment between the working definition of wellbeing chosen and the model adopted. Such alignment between definition and model allows for assessments to be 
chosen and developed that fit with both the definition of wellbeing and model being used.

Beyond definitions and models, consideration also needs to be given to the content that is being assessed (i.e., the what), the process of assessment (i.e., the how), and the systems involved (i.e., the who). The next three sections consider these aspects in more detail.

\section{The Content of Assessment}

While the definition and model can guide the focus of assessment, the next question is what should be included in the assessment-the content. From a psychometric perspective, perhaps one of the most accessible resources for considering the content of an assessment is the OECD's (2013) Guidelines on Measuring Subjective Wellbeing. This guide points to the need for considering conceptual frameworks, validity, and accuracy, along with various methodological considerations such as question construction, response formats, cultural considerations, order effects, and survey context, to name just a few. Various aspects of implementation are also considered. The OECD recommends assessing life evaluation, affect, experienced wellbeing, and domain wellbeing, and they provide examples of how to do so. However, while the guidelines provide a comprehensive and useful resource, one drawback is that the recommendations largely apply to adults, and thus are more relevant for teachers, school staff, parents, and carers. The same guidelines, especially in relation to the content that is included in an assessment, may or may not be appropriate for young people.

Some measures specific to children and adolescents do exist. For example, The Children's Society (2019) in the U.K. developed the Good Childhood Index which measures life satisfaction, happiness, and wellbeing in ten key areas of children's lives (e.g., friends, home, appearance, school). Huebner, Suldo, and Valois (2003) developed a widely used 7-item life satisfaction scale and the 5-item brief multidimensional student life satisfaction scale. Kern, Benson, Steinberg, and Steinberg (2016) developed the EPOCH Measure of Adolescent Well-being, which measures five positive psychological characteristics: Engagement, Perseverance, Optimism, Connectedness, and Happiness. Still, until recently, less attention has been given to the development and validation of measures and best practice approaches for capturing children's wellbeing (Rose et al., 2017; Stevens \& Jarden, 2019).

One consideration in determining the content to be included in an assessment is the underpinning model of wellbeing that the school is embracing, to ensure the assessment captures all elements of the relevant model. The 
model is the prerequisite base from which to link the wellbeing assessment to, and as such, no assessment should take place until an appropriate model and definition of wellbeing has been identified and clarified. A measure that has evidence of validity and reliability is of little use if it is misaligned with the school's way of understanding wellbeing.

We suggest that it is important to not only consider wellbeing itself, but also what might be impacting upon and driving wellbeing. For example, let us say a school is working with the PERMAH model, and has implemented a program that aims to build high-quality connections (Dutton \& Heaphy, 2003) in the staff, with the intention of building better relationships amongst staff (the "R" in PERMAH). The assessment should include a measure of relationships, ensuring that the program achieves its intended outcomes. But the assessment might also include the other elements of PERMAH, global perspectives of wellbeing (e.g., life satisfaction, work satisfaction, overall happiness), as well as personal and social characteristics of the staff. That is, it is often beneficial if wellbeing assessments not only aim to assess the impacts of positive education initiatives and changes in school community wellbeing over time (i.e., "did it work?"), but also have enough sophistication and investigative depth to decipher potential broader impacts of the program and to identify which elements are driving any impactful changes. For instance, it may be possible that the PERMAH element of "Relationships" does not change as a result of the high-quality connections program, but the program helps staff enjoy themselves (Positive emotion increased), they develop a greater sense of meaning (Meaning increased), and generally are more satisfied with their life as a whole. Further, the program might have been useful for primary level teachers and not for secondary teachers or depend upon how introverted or extraverted the staff member is. Such information allows the practitioner to then investigate if the effects of the program may be delayed, or due to other contextual factors, or if the program was not successful and another approach may be needed to bolster that element of "Relationships" in PERMAH. As the common business saying goes, "you can only manage what you measure". More comprehensive assessments can allow better management, because well designed assessments allow for data-driven decision-making.

At the same time, comprehensiveness must be balanced across the length of assessment and participant burden in the particular context of use (Lopez \& Snyder, 2003; OECD, 2013; Rolstad, Adler, \& Ryden, 2011). If assessments are too long, students may not take them seriously or lose focus, which then impacts data quality (validity and reliability). Therefore, there is a pragmatic 
aspect of what can be asked of students, especially younger students. Likewise, all data captured should be planned to be used, as it is a waste of time and resources to capture information that is not used.

\section{The Process of Assessment}

Once one determines what should be included, the next question becomes how assessment should be done, or the process involved. The process of assessment refers to the mode (e.g., self-report versus observation, online versus offline), context and setting, frequency, and timeline of assessments. One thing to consider is whether assessment is meant to provide a cross-sectional snapshot across an array of areas, versus longitudinal tracking of wellbeing and changes in wellbeing over time. Although there is no specific assessment practice data in schools to draw on, from our experience, cross-sectional assessments of wellbeing in school communities are the most common practice. The cross-sectional assessments sample different individuals without the need to link responses over time. By comparing responses from one year to another, trends across the school can be identified, testing for example whether adding a wellbeing program during the year increased how students on average performed in their classes. There are several reasons why schools might opt for a single cross-sectional snapshot. It is challenging to assess the same individuals over time and link their data, especially with very few assessment platforms suitable for this purpose. With snapshots, responses can be kept anonymous, potentially increasing comfort in revealing sensitive information. It is also less time and resource intensive for both schools and participants. But it also means that there is a greater amount of between person variance, and numerous other factors that could be contributing to differences, including historical events, characteristics of a particular group of students, the timing of the assessment, and other confounding factors (Shaughnessy, Zechmeister, \& Zechmeister, 2014).

In contrast, longitudinal tracking of wellbeing involves multiple assessment points tracking the same individuals over time and assessing change at both the individual and group level. Longitudinal assessments more directly look at changes in wellbeing over time, along with pointing to potential predictors, enablers, and barriers to wellbeing as an outcome. But such data is much harder to capture, as students change classes and schools. Data must be identifiable or linkable in some ways, which can increase desirability responding (OECD, 2013). Participants can tire of completing the same survey multiple times or adjust their responses as the assessment becomes predictable. The inclusion of identifiable mental health information raises 
a number of ethical questions around young people's rights, confidentiality, and protection (Kern et al., 2020). In addition, some psychometric measures, especially those with short response scales (e.g., a Likert scale ranging from 0 to 4 ), are often not sensitive to capturing change over time, and are thus only suitable for cross-sectional use (OECD, 2013).

Another important issue related to assessment process is the use of test norms and comparisons. Our experience is that norms are often not useful, unless the assessment is a one-off cross-sectional snapshot. For most wellbeing measures, while diverse participants may have been included in the development and testing of the measure, they are often not representative of different populations, and thus may be an inappropriate comparison point to the school's population. In addition, if one's school is reported to be higher than the comparison group, this can cause complacency and lack of continued investment in wellbeing. Alternatively, if one's school is reported to be lower than the comparison group, this may cause feelings of hopelessness. We recommend capturing longitudinal data over several time points, as any change from baseline provides valuable information regarding the implementation of positive education initiatives. This changes the focus from "others" which a school or practitioner cannot control, to "your school" and aspects that are more within the schools and practitioners' control. Such an approach assists in setting growth and approach-based targets and aspirations for schools.

To enable the incorporation of regular assessment of wellbeing, it can be beneficial to link and align wellbeing data with data the school already routinely collects, such as academic achievement or behavioural data (e.g., absences, bullying). Analysis of the link between these datasets can provide useful information attuned to the interests of diverse stakeholders across the school community.

\section{The Systems Being Assessed}

Beyond the content and process involved, consideration should be given to who should be involved in assessments within the school community. A systems informed perspective suggests that different perspectives are valuable, and there is value in considering assessment at different levels within a system (Kern et al., 2020). Within a school community, as illustrated in Fig. 12.1 (Jarden \& Jarden, 2016, p. 427, used with permission), wellbeing assessments and programs can happen at three distinct levels, regardless of the structure or size of the school community: the individual level ( $M e$; such as a student, a teacher, a parent), the group level (We; such as pairs of students, 


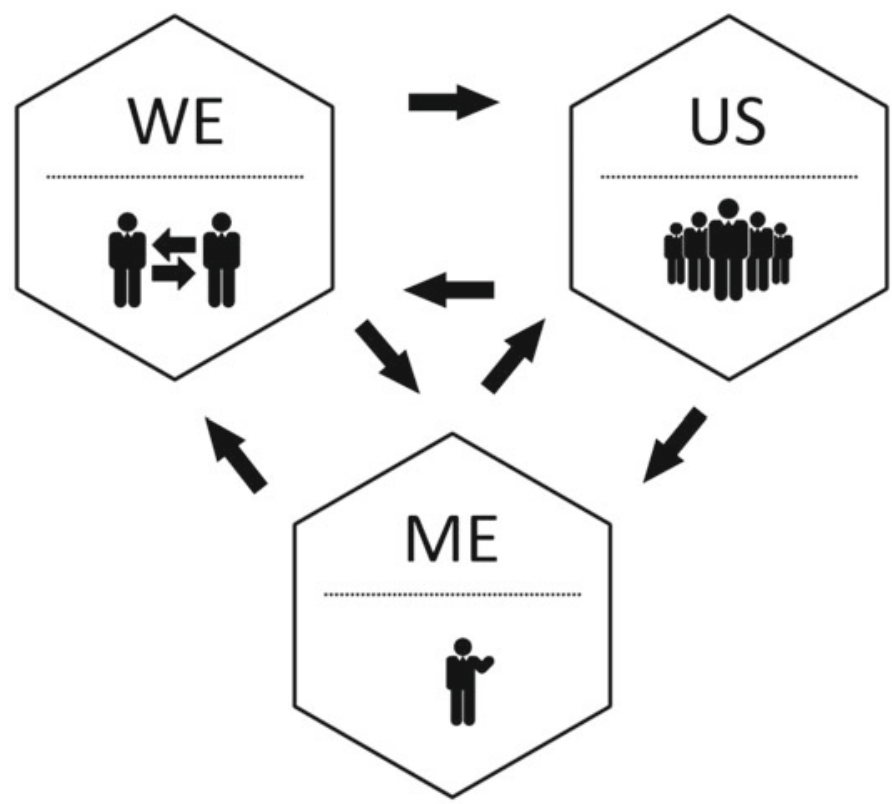

Fig. 12.1 Me, We, and Us levels of wellbeing in a system (Original image published in Jarden, A., \& Jarden, R. (2016). Positive psychological assessment for the workplace. In L. Oades, M. F. Steger, A. Delle Fave, \& J. Passmore (Eds.), The Wiley-Blackwell handbook of positive psychology at work (pp. 415-437), by John Wiley \& Sons. This image is licensed under an All Rights Reserved License, and is not available under a Creative Commons license)

the student, and teacher, the teacher and parent, the class), and the organizational level ( $U s$; such as the school as a whole). These levels are inter-related and co-dependent, and each reveals unique but important information about the wellbeing of the school community as a whole.

Individual-level $(\mathrm{Me})$ wellbeing initiatives include strategies and tasks that teachers or students can do by themselves, such as learning about and utilizing their strengths or undertaking a mindfulness program (Niemiec, 2013). In such cases, measures such as the Strength Use and Knowledge Scale (Govindji \& Linley, 2007) or the Mindful Attention Awareness Scale (Brown \& Ryan, 2003) might be used for assessment of these constructs. Group level (We) wellbeing initiatives include strategies and tasks that involve the individual working on their wellbeing with at least one other person that they are directly in contact with on a regular basis, such as job crafting (Wrzesniewski, 2014) or building high-quality connections (Dutton \& Heaphy, 2003), and for students strategies and tasks such as delivering gratitude letters to favourite teachers (Norrish, 2015). In such cases, job crafting could be assessed with the Job Crafting Questionnaire (2013), and high-quality connections could be 
assessed with various connection measures (Dutton, 2003). Organizational and whole school level $\left(U_{s}\right)$ wellbeing initiatives include strategies and tasks that aim to have an impact over the whole of the school community, such as creating a school wellbeing policy (HAPIA, 2009) or framework, directing resources towards one-off or smaller scale wellbeing initiatives, whole of school wellbeing assessments, or Appreciative Inquiry (AI) summits (Cooperrider \& Whitney, 2005). The $U_{s}$ level is best assessed with global wellbeing measures that are anchored to the school's definition of and model of wellbeing - these could include scales such as the Happiness Measures (Fordyce, 1988) or Flourishing Scale (Diener et al., 2009).

These levels of Me, We, and Us can also be integrated for maximal effect. For example, in a school setting a teacher $(M e)$ can choose to identify and work on their strengths (e.g., an individual strengths assessment such as the Strength Profile: www.strengthsprofile.com). A team (We) can choose to focus on team members strengths in the deployment of team projects (e.g., comparing strengths profiles or different patterns of strengths knowledge and use-Govindji \& Linley, 2007). The school ( $\left.U_{s}\right)$ can choose to invest in the cost of a strengths development program for all teachers and school staff, or focus on combined organizational strengths during an AI summit.

All three of these levels require different assessment approaches, with arguably the $M e$ level easiest to assess, followed by the We level, with the Us level the hardest, based upon our current validated assessment measures. Some measures at each level do exist. For example, at the individual $(\mathrm{Me})$ adult level, wellbeing measures include the Satisfaction with Life Scale (Diener, Emmons, Larson, \& Griffin, 1985), the Subjective Happiness Scale (Lyubomirsky \& Lepper, 1999), and the Hope Scale (Snyder et al., 1991), for children the Good Childhood Index (Children's Society, 2019) and Student Life Satisfaction Scale (Huebner et al., 2003), and for adolescents the EPOCH Measure of Adolescent Well-being (Kern et al., 2016). At the group levels (We), measures such as the Workplace Wellbeing Index (Page, 2005) or Work on Wellbeing (Jarden \& Jarden, 2016) capture team functioning. At the organization $\left(U_{s}\right)$ level, individuals might reflect upon the organization more globally (e.g., "does your organization invest in wellbeing?"), or measures such as the School Wide Evaluation Tool (Center on Positive Behavioral Interventions and Supports, 2019) captures school-wide features impacting upon behaviour and functioning.

At present, arguably, much of the emphasis within education focuses on individuals. Further, when the group and organization levels are considered, measures typically involve the aggregation of individual responses of persons within the team or organization. From a systems perspective, the whole (e.g., 
capturing the wellbeing of the community) is more than the sum of the parts (Allison, Waters, \& Kern, 2020; Kern et al., 2020). A key priority becomes how to best integrate these levels, which are integral to the school community context, with appropriate assessment within and across levels. How exactly these levels are integrated, and what possibilities for integration exist, is yet to be investigated, so is largely unknown. For example, a question from a school might be "should we start at the Me level, then progress to the We level, and then progress to the Us level, or should we do it the other way around?", or it could be "should we start at all three levels simultaneously?" It is also unknown how to best capture the levels and integrations between the levels. In practice, schools have already started at one or more of these levels and so the challenge is to broaden, capture valid data across the levels, which may point to a natural starting point at one level that is more obvious. Yet within this integration perhaps lies the great possibility to increase organizational and educational performance and flourishing, as we move towards "opening the possibility for yet unimagined solutions that allow both current and future generations to thrive" (Kern et al., 2020, p. 714). Nonetheless, a systems perspective highlights the idea that both assessing wellbeing and intervening at different possible levels within school communities may be one of the best pathways to increasing overall and long-term wellbeing and sustaining it.

The language and idea of $M e, W e, U s$ provides a "wellbeing literacy" (Oades, 2020) that is easily understandable and communicable to both decision-makers, leaders, and staff, providing an accessible approach for turning this priority into a reality. However, there is no measure, scale, or tool that holistically accounts adequately for all three levels of the $M e$, We, Us. At most it is our contention that further consideration of the We and $U_{s}$ levels, along with intersections and relationships amongst the three levels, is both needed and would be beneficial-both in practice, and from a research intervention and assessment perspective. ${ }^{2}$ We contend that it is time to consider the $M e, W e, U_{s}$ framework for guiding the implementation and assessment of wellbeing programs.

\section{Wellbeing Assessment Tools}

There are many wellbeing assessment tools available, which range greatly in quality. Some have been validated, some have been widely used despite being

\footnotetext{
${ }^{2}$ Social Network Analysis is one approach that does provide some optimism in this regard, however is seldom used in positive education research.
} 
of poor quality, some provide feedback to users, some provide data that are more useful than others, some are free and some are expensive, and some are more reliable (from a technology perspective) than others. We contend that validity is the benchmark for good assessment. Validity means that the assessment actually measures what it says it measures and it consistently measures the same things each time it is used (reliability). It is no easy job to determine whether a psychometric tool is valid or reliable, so we encourage test users to gain expert insight from individuals or consultants knowledgeable about psychometric testing and test properties. As a bare minimum, the test providers should provide information about the psychometric properties of their measures, which ideally have been peer-reviewed.

We contend that no measure, no matter how shiny or cheap, should be used unless you can rely on its psychometric properties. Table 12.1 provides a few examples of measures that have been validated in the literature. This list is in no way exhaustive, but rather provides an illustration of some of the sound tools currently available.

\section{Examples of a Wellbeing Assessment Tool in Practice}

To make the use of tools more concrete, we describe examples of how the Wellbeing Profiler (https://www.wbprofiler.com) was beneficially used as part of positive education efforts within an educational community. As summarized in Table 12.1, the Wellbeing Profiler is a measurement and reporting service developed for schools to examine the wellbeing of their students from ages 10 to 25 years old. The Profiler measures wellbeing in 6 domains (Emotional and Strengths, Psychological, Cognitive, Social, Physical, and Economic) as identified in the research literature as important indicators of youth wellbeing (Chin, 2017; Slemp et al., 2017).

The Centre for Wellbeing Science at the University of Melbourne in Australia has used the Wellbeing Profiler to develop or refine the wellbeing strategies and plans in schools across the three main education sectors in Australia (Catholic, government, and independent) since 2015, as well as local government agencies and networks in Australia (as described below). Areas of cohort strengths and concerns have been identified through needs analysis of the aggregate data, providing schools and councils with rich information to assist with allocating appropriate funding and resources for targeted interventions and support for young people in their care.

For example, since 2016, Maroondah City Council (outer east suburbs of Melbourne, Australia) has utilized the Wellbeing Profiler to collect data from young people attending school in the municipality. The project initially 


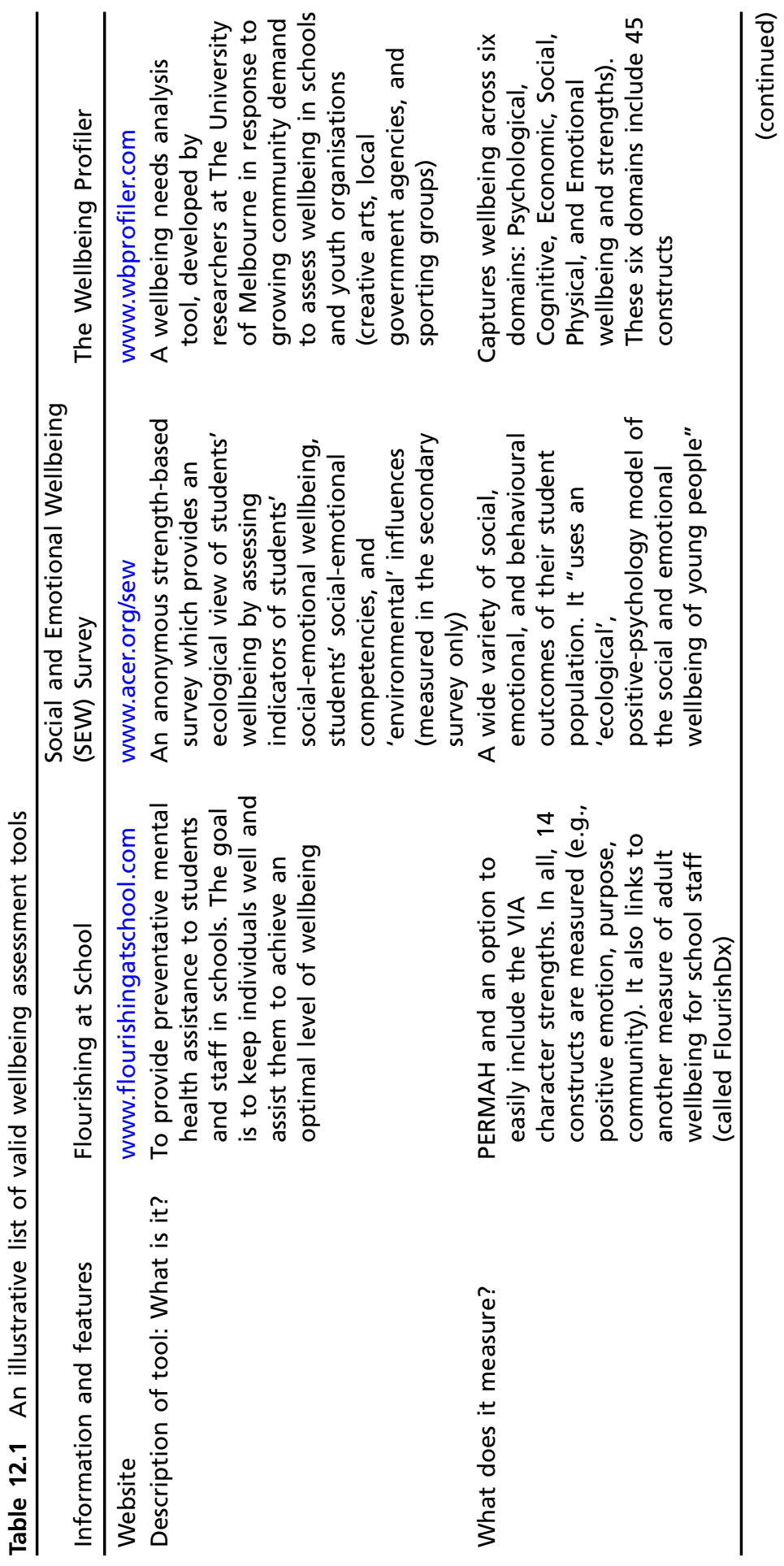




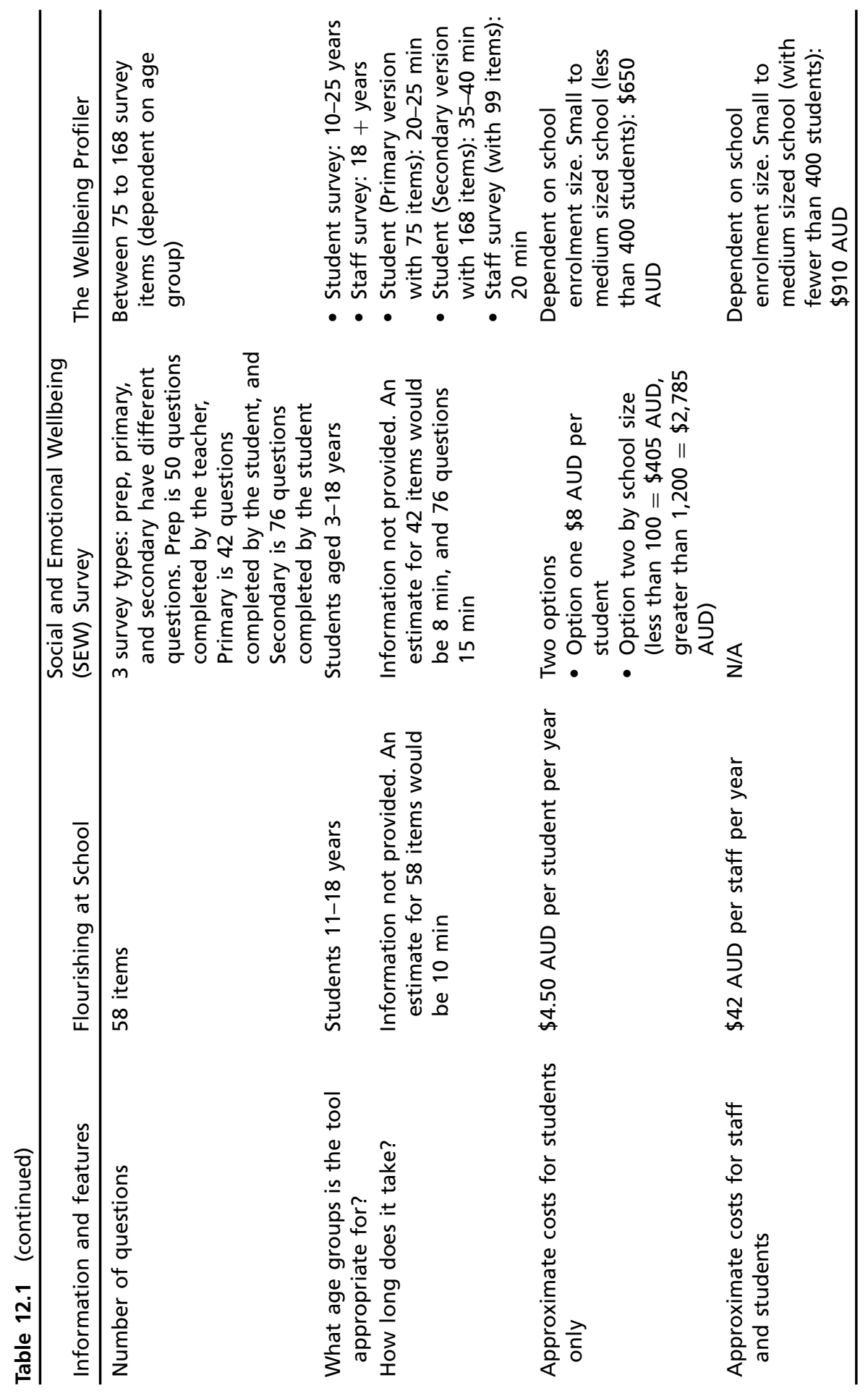




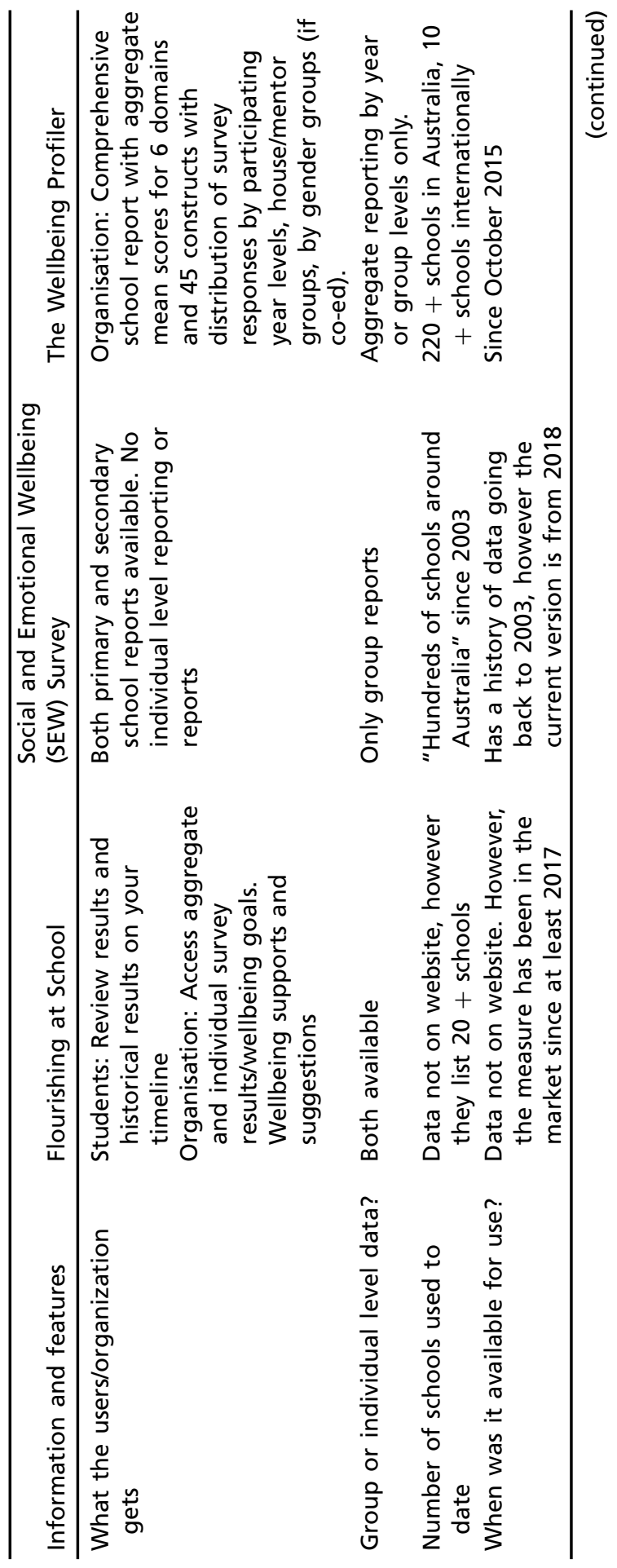


A. Jarden et al.




involved 4,777 students between the ages of 10 and 20 years from 19 different education settings (11 primary schools, 7 secondary schools, and students in a professional diploma program ${ }^{3}$ : Chin, Jiang, \& Vella-Brodrick, 2016). Maroondah City Council (2017) used the survey findings and report recommendations to inform their 2017-2019 Youth Strategy Action Plan. This collaborative partnership has since grown to include all 27 government schools in the local municipality and has also attracted additional project funding from the Department of Education and Training in Victoria to undertake a whole of systems approach in 2019 to measure and understand the wellbeing needs of staff, students, and their parents/carers.

A second collaborative partnership occurred with the Rural City of Wangaratta (Victoria, Australia), where over 1,400 young people across eight schools and youth service providers participated in the Wellbeing Profiler survey (Chin \& Vella-Brodrick, 2018). The regional council utilized the survey findings and recommendations to inform their 2019-2021 Youth Action Plan (Rural City of Wangaratta, 2019). Similar to Maroondah City Council, youth strategies and plans were developed to address the identified needs of their youth, which included physical health indicators (such as sleep quality and quantity, physical and sedentary activities, perception of overall health, and physical self-concept); mental health and emotional wellbeing outcomes (including happiness, resilience, risk factors such as anxiety, stress, anger); and as adaptive (cognitive reappraisal) and maladaptive (suppression and rumination) emotion regulation strategies.

Through collaborating with grassroots organizations and schools, the Wellbeing Profiler has provided valid and reliable data to guide wellbeing policy planning, training, and to help determine how resources are best utilized. The survey findings and recommendations from the commissioned school and research reports have led to more targeted planning and development of evidence-based strategies to address identified needs across local networks of schools. This impact is evident from the use of data from the commissioned reports to shape local councils' youth strategy plans and policy documents (e.g., Maroondah City Council Youth Strategy, 2017). In addition, the localized data have been used to inform the participating schools' annual implementation plans to address, plan and develop future programs. Importantly, the Wellbeing Profiler reports have provided the partner organizations with enhanced capacity to seek external funding to develop targeted interventions to address the identified needs from the reports, with the councils securing between $\$ 890,000$ AUD and $\$ 2.7$ million AUD in funding to

3VCAL students in one TAFE—known as 'Technical And Further Education' in Australia. 
advance their positive education efforts. The valid assessment of wellbeing through the Profiler has been critical to these successes.

\section{Questions to Consider for an Assessment}

While there are many tools available, the process of determining the right wellbeing assessment for a school can be daunting. There is no one right measure or approach, as what is right and useful depends on the specific context of the school, including the intentions of the assessment, the model of wellbeing, the stakeholders involved, and the time and resources available. When considering whether or not to use a particular tool, we find that it is helpful to consider a series of questions, which together can aid in this decision-making process.

First, we encourage you to ask these three questions:

1. What type or model of wellbeing does the assessment tool measure? Does that model align with your schools' model of wellbeing?

2. Has the complete assessment measure (the assessment battery, based on all questions included) been validated as a whole (not just some of the measures that might be included in the tool) and published in peer-reviewed literature?

3. Who owns the data, who has access to the raw data, and how can the data be used? Different standards often apply for internal school reporting purposes versus research purposes, so your intentions with using the data, and making sure you can meet those intentions with the data that will be available to you, is helpful.

These are the three most important questions. If the answer is unclear to any one of them, we suggest that undertaking the use of an assessment measure may be risky and advise against it. If the answers are clear, Table 12.2 outlines some further questions to consider for thinking about how valid and useful the tool might be for your purposes.

There are no right or wrong answers to these questions. Rather, we suggest that you consider the potential value of the tool based on your needs and purposes in conducting the assessment. Key aspects that these questions focus on include psychometric appropriateness, survey and tool flexibility, user experience, data use and safety, and fit for purpose and alignment with the school's model of wellbeing. 
Table 12.2 Questions to consider in thinking about the validity and usefulness of an assessment tool

How was the assessment measure developed? Did the development follow standard test development procedures (see Boateng, Neilands, Frongillo, Melgar-Quiñonez, \& Young, 2018; Shum et al., 2013)? If so, were those tests performed by someone suitably qualified to do so?

How expensive is the assessment measure? Do you have sufficient resources available? Will a more expensive measure provide a better return on investment? How reliable is the infrastructure for administering the tool? For instance, if using an online measure, are there any log-in or account problems or resource bandwidth issues? You might ask the providers whether other schools have had issues with this tool in the last year, and if so, when, what, and to what extent were the issues

How many schools have used the assessment tool in the last year, and is it possible to contact two of them for their opinions and perspectives?

Does the assessment tool comply with all industry standards and local regulations for data storage and safety in the country it is being used?

Does the tool comply with the privacy legislation for your city/state/country?

What are the main benefits of using this assessment tool over choosing one of the others available?

How flexible is the measure? For instance, can you easily adjust when the tool is administered, add users, or change the questions that are included to fit your context?

Who administers the assessment? Who is involved and how does the process work? Is the process transparent or does it operate behind a black box?

Does the measure include the opportunity to capture qualitative data?

What age ranges are the assessment tool suitable for, and do different age ranges get different assessments?

Has the tool been reviewed by an ethics review board? What ethical issues might the tool bring? How does the tool handle consent or assent procedures?

What data, visual graphs, and reports will you receive at the end of the measurement? What is reported back to the individual respondent versus the school?

How long on average does the assessment take for students and adults of different learning abilities and backgrounds? How often is the assessment recommended?

Can the measure easily track the same individuals over time? How easily can the data be linked to other information?

Is the assessment tool available in additional languages? Does it include the languages spoken by people within your school?

Is the assessment measure available in additional formats? (e.g., paper-based, mobile-based, text message)

Does the assessment tool work robustly on all technological platforms or devices (e.g., phones, tablets, various web browsers)? 
Table 12.2 (continued)

Does the assessment tool align with the objectives you have for your school's assessment?

Does the assessment tool have functionality related to duty of care, such as where students report low wellbeing or mental health issues? How are these aspects managed and reported?

Assessments create opportunities for conversations about wellbeing, and conversations about wellbeing focus individual's attention on wellbeing and in themselves improve wellbeing. In this regard, what does your tool provide to the users (e.g., individual-level reports, organizational level reports, summaries, onscreen graphs, suggested actions, raw data)?

While these questions largely relate to the assessment tool that could aid in your school's positive education efforts, two further questions are also important to consider in the broader context of wellbeing assessments as a whole:

1. How receptive are students and teachers in your school to positive education?

2. How much energy and sense of propriety is there for positive education in your school?

If you do not know, how could you find out? Could answering these questions be part of the initial assessment? Answers to questions like these can also support assessment decisions. For example, if receptivity, energy, and proprietary are low, then a short, less frequent wellbeing assessment battery would be optimal. It is also possible that at one point you may choose not to use a formal assessment tool at all, but rather many insights and conclusions may be drawn from data your school already collects - this may include data relating to attendance, behaviour management, referrals to school counsellors (positive and negative), and academic improvements.

\section{Conclusion}

A growing amount of evidence is demonstrating that wellbeing is beneficial to workplaces (e.g., Foresight, 2008; Jarden \& Jarden, 2016; Lewis, 2011; Oswald, Proto, \& Sgroi, 2009; Rath \& Harter, 2010), schools (e.g., Jarden $\&$ Jarden, 2015; Norrish, 2015; PESA, 2020; Waters, Sun, Aarch, \& Cotton, 2016), families (e.g., Conoley, Winter-Plum, Hawley, Spaventa-Vancil, \& Hernandez, 2015; Sheridan \& Burt, 2009), and communities as a whole (e.g., Neto \& Águeda, 2014; Schueller, 2009). The question then becomes 
how to cultivate and sustain wellbeing in schools. We suggest that assessment plays a critical role. This chapter has summarized some of the basics of assessment and outlined wellbeing assessments in schools: what assessments are, why assessments are important, and examples of good assessment in practice. We stressed the importance of a systems lens and highlighted the $M e, W e, U_{s}$ framework, demonstrated the benefits of assessment data in decision-making, and provided a comprehensive list of questions schools and decision-makers may find useful in considering assessment tools and approaches.

It is our hope that high-quality psychological wellbeing information can be obtained with a focus on practices that are theoretically and research based, and then be used to create positive school environments where staff and students are able to engage in meaningful and enjoyable work and learning that taps into their greatest strengths and their most important goals. With such information, schools can capitalize on the unique intellectual and personal strengths of each student and staff member. Rather than focusing on making staff and students to do more work and learning, the focus can be on how to enable them to do good work and learning based on the strengths and values of that person and what they can contribute to others within the school community. Coupled with good wellbeing assessment that acknowledges and captures different types of information, we contend that schools can go beyond fixing problems to promote excellence in a more sustainable way for every individual within and beyond the school community.

\section{References}

Aked, J., \& Thompson, S. (2011). Five ways to wellbeing: New applications, new ways of thinking. London: New Economics Foundation.

Allison, L. M., Waters, L., \& Kern, M. L. (2020). Flourishing classrooms: Applying a systems-informed approach to positive education. Contemporary School Psychology. https://doi.org/10.1007/s40688-019-00267-8.

Boateng, G. O., Neilands, T. B., Frongillo, E. A., Melgar-Quiñonez, H. R., \& Young, S. L. (2018). Best practices for developing and validating scales for health, social, and behavioral research: A primer. Frontiers in Public Health, 6(149), 118. https://doi.org/10.3389/fpubh.2018.00149.

Brown, K. W., \& Ryan, R. M. (2003). The benefits of being present: Mindfulness and its role in psychological well-being. Journal of Personality and Social Psychology, 84, 822-848.

Cambridge English Dictionary. (2019a). Assessment. Retrieved 28 October 2019 from https://dictionary.cambridge.org/dictionary/english/assessment.

Cambridge English Dictionary. (2019b). Evaluation. Retrieved 28 October 2019 from https://dictionary.cambridge.org/dictionary/english/evaluation. 
Cambridge English Dictionary. (2019c). Testing. Retrieved 28 October 2019 from https://dictionary.cambridge.org/dictionary/english/testing.

Center on Positive Behavioral Interventions and Supports. (2019). School wide evaluation tool. https://www.pbis.org/resource/school-wide-evaluation-tool-set.

Chin, T-C. (2017). Keeping up with the times: A considered approach to measuring youth well-being. In M. White, G. R. Slemp, \& S. Murray (Eds.), Future directions in well-being: Education, organizations, and policy (pp. 47-51). Adelaide, SA, Australia: SPC Press.

Chin, T.-C., Jiang, J., \& Vella-Brodrick, D. A. (2016). Understanding the needs of young people in Maroondah: Findings from the student well-being survey. The University of Melbourne, VIC, Australia. Commissioned by Maroondah City Council.

Chin, T.-C., \& Vella-Brodrick, D. A. (2018). Understanding the needs of young people in Wangaratta: Findings from the student well-being survey. The University of Melbourne, VIC, Australia. Commissioned by the Rural City of Wangaratta.

City of Maroondah. (2017). Youth strategy: Raising the wellbeing of Maroondah's young people. http://www.maroondahyouth.com.au/files/assets/youth/documents/ youth-strategy-2017.pdf.

Conoley, C., Winter-Plum, E., Hawley, K. J., Spaventa-Vancil, K. Z., \& Hernandez, R. J. (2015). Integrating positive psychology into family therapy: Positive family therapy. The Counseling Psychologist, 43(5), 703-733. https://doi.org/10.1177/ 0011000015575392.

Cook, D. A., \& Beckman, T. J. (2006). Current concepts in validity and reliability for psychometric instruments: Theory and application. The American Journal of Medicine, 119, 166.e7-166.e16. https://doi.org/10.1016/j.amjmed.2005.10.036.

Coolican, H. (2014). Research methods and statistics in psychology (6th Ed.). Psychology Press.

Cooperrider, D., \& Whitney, D. (2005). Appreciative inquiry: A positive revolution in change. San Francisco: Berrett-Koehler Publishers.

Crisp, R. (2017). Well-being. In E. N. Zalta (Ed.), The Stanford encyclopedia of philosophy. https://plato.stanford.edu/archives/fall2017/entries/well-being/.

Diener, E. (Ed.). (2009). Assessing well-being: The collected works of Ed Diener. New York, NY, USA: Springer Science + Business Media. http://dx.doi.org/10.1007/ 978-90-481-2354-4.

Diener, E., Emmons, R. A., Larson, R. J., \& Griffin, S. (1985). The satisfaction with life scale. Journal of Personality Assessment, 49, 71-75.

Diener, E., Wirtz, D., Tov, W., Kim-Prieto, C., Choi, D., Oishi, S., \& BiswasDiener, R. (2009). New measures of well-being: Flourishing and positive and negative feelings. Social Indicators Research, 39, 247-266.

Dutton, J. (2003). Energize your workplace: How to create and sustain high quality connections at work. San Francisco: Jossey-Bass.

Dutton, J., \& Heaphy, E. (2003). The power of high quality connections. In K. Cameron, J. Dutton, \& R. Quinn (Eds.), Positive organizational scholarship: Foundations of a new discipline (pp. 263-278). San Francisco: Berrett - Koehler. 
Fordyce, M. W. (1988). A review of research on the happiness measures: A sixty second index of happiness and mental health. Social Indicators Research, 20, 6389.

Foresight. (2008). Foresight mental capital and wellbeing project: Final project report. London: The Government Office for Science. http://www.bis.gov.uk/foresight/ our-work/projects/current-projects/mental-capitaland-wellbeing.

Govindji, R., \& Linley, P. A. (2007). Strengths use, self-concordance and well-being: Implications for strengths coaching and coaching psychologists. International Coaching Psychology Review, 2(2), 143-153.

HAPIA. (2009). Best practice guidelines: Workplace health in Australia. Sydney: Health and Productivity Institute of Australia.

Hone, L., Jarden, A., \& Schofield, G. (2014). Psychometric properties of the Flourishing Scale in a New Zealand sample. Social Indicators Research, 119(2), 1031-1042.

Hone, L., Jarden, A., Schofield, G. M., \& Duncan, S. (2014). Measuring flourishing: The impact of operational definitions on the prevalence of high levels of wellbeing. International Journal of Wellbeing, 4(1), 62-90. https://doi.org/10. 5502/ijw.v4i1.1.

Huebner, S. E., Suldo, S. M., \& Valois, R. F. (2003, March 12-13). Psychometric properties of two brief measures of children's life satisfaction: The Students' Life Satisfaction Scale (SLSS) and the Brief Multidimensional Students' Life Satisfaction Scale (BMSLSS). Paper prepared for the Indicators of Positive Development Conference. https://www.childtrends.org/wp-content/uploads/2013/05/ Child_Trends-2003_03_12_PD_PDConfHSVP.pdf.

Iasiello, M., Bartholomaeus, J., Jarden, A., \& Kelly, G. (2017). Measuring PERMA+ in South Australia, the state of wellbeing: A comparison with national and international norms. Journal of Positive School Psychology, 1(2), 53-72.

Jarden, A., \& Jarden, R. (2015). Applied positive psychology in higher education. In M. Henning, C. Krägeloh, \& G. Wong-Toi (Eds.), Student motivation and quality of life in higher education (pp. 37-44). London: Routledge.

Jarden, A., \& Jarden, R. (2016). Positive psychological assessment for the workplace. In L. Oades, M. F. Steger, A. Delle Fave, \& J. Passmore (Eds.), The Wiley-Blackwell handbook of positive psychology at work (pp. 415-437). Published Online: John Wiley \& Sons. https://doi.org/10.1002/9781118977620.ch22.

Jarden, A., Rashid, T., Roache, A., \& Lomas, T. (2019). Ethical guidelines for positive psychology practice (version 1.0: English). International Journal of Wellbeing, 9(3), 1-30. https://doi.org/10.5502/ijw.v9i3.921.

Kern, M. L., Benson, L., Steinberg, E. A., \& Steinberg, L. (2016). The EPOCH measure of adolescent well-being. Psychological Assessment, 28, 586-597.

Kern, M. L., Cahill, H., Morrish, L., Farrellu, A., Shlezinger, K., \& Jach, H. (2020). The responsibility of knowledge: Identifying and reporting students with evidence of psychological distress in large-scale school-based studies. Research Ethics. https://doi.org/10.1177/1747016120952511. 
Kern, M. L., Williams, P., Spong, C., Colla, R., Sharma, K., Downie, A., Taylor, J. A., Sharp, S., Siokou, C., \& Oades, L. G. (2020). Systems informed positive psychology. Journal of Positive Psychology, 15, 705-715. https://doi.org/10.1080/ 17439760.2019 .1639799$.

Lewis, S. (2011). Positive psychology at work: How positive leadership and appreciative inquiry create inspiring organizations. Malden, MA: Wiley-Blackwell.

Lopez, S. J., \& Snyder, C. R. (Eds.). (2003). Positive psychological assessment: A handbook of models and measures. Washington, DC, USA: American Psychological Association. http://dx.doi.org/10.1037/10612-000.

Lyubomirsky, S., \& Lepper, H. S. (1999). A measure of subjective happiness: Preliminary reliability and construct validation. Social Indicators Research, 46, 137-155.

Maroondah City Council. (2017). Youth strategy: Raising the wellbeing of Maroondah's young people. Victoria: Maroondah City Council. http://www.maroondah.vic.gov. $\mathrm{au} /$ files/assets/public/documents/strategies/youth-strategy-1.pdf.

Michaelson, J., Mahony, S., \& Schifferes, J. (2012). Measuring well-being: A guide for practitioners. London: New Economics Foundation.

Neto, L. M., \& Águeda Marujo, H. (2014). Positive community psychology and positive community development: Research and intervention as transformativeappreciative actions. In H. Águeda Marujo \& L. Neto (Eds.), Positive nations and communities: Cross-cultural advancements in positive psychology (vol 6). Dordrecht: Springer.

Niemiec, R. (2013). Mindfulness and character strengths: A practical guide to flourishing. Gottingen, Germany: Hogrefe Publishing.

Noble, T., \& Mcgrath, H. (2015). PROSPER: A new framework for positive education. Psychology of well-Being, 5, 1-17. https://doi.org/10.1186/s13612015-0030-2.

Norrish, J. (2015). Positive education: The Geelong grammar school journey. Oxford: Oxford University Press.

Oades, L. (2020). Towards a wellbeing literate society. In K. Andrews, F. Papps, L. Mancini, K. Nicholson-Perry, G. Senior, \& E. Brymer (Eds.), Innovations in a changing world (pp. 14-18). Australia: Australian College of Applied Psychology.

Oades, L., \& Heazlewood, F. (2017). Wellbeing language and definitions guide. Sydney, NSW, Australia: Mental Health Commission of NSW. https://wbcnsw. files.wordpress.com/2017/09/language-and-definitions-guide-web.pdf.

Organisation for Economic Co-operation and Development (OECD). (2013). OECD guidelines on measuring subjective well-being. OECD Publishing. http:// dx.doi.org/10.1787/9789264191655-en.

Oswald, A. J., Proto, E., \& Sgroi, D. (2009). Happiness and productivity (IZA Discussion Paper 4645). Institute for the Study of Labor.

Page, K. (2005). Subjective wellbeing in the workplace (Unpublished honours thesis). Deakin University, Melbourne, VIC, Australia.

Penn State University. (2019). Differences between testing, assessment, and evaluation. http://tutorials.istudy.psu.edu/testing/testing2.html. 
Positive Education Schools Association (PESA). (2020). Positive education framework: A guide to understanding and implementing positive education. https://www. pesa.edu.au/.

Rath, T., \& Harter, J. (2010). The economics of wellbeing. Washington, DC: Gallup Press.

Rolstad, S., Adler, J., \& Ryden, A. (2011). Response burden and questionnaire length: Is shorter better? A review and meta-analysis. Value in Health, 14, 11011108. https://doi.org/10.1016/j.jval.2011.06.003.

Rose, T., Joe, S., Williams, A., Harris, R., Betz, G., \& Stewart-Brown, S. (2017). Measuring mental wellbeing among adolescents: A systematic review of instruments. Journal of Child and Family Studies, 26, 2349-2362. https://doi.org/10. 1007/s10826-017-0754-0.

Rural City of Wangaratta. (2019). 2019-2021 youth action plan. https://www.wan garatta.vic.gov.au/wyap.

Rusk, R., \& Waters, L. (2015). Exploring the underlying components of positive psychology interventions: Five domains of positive function. Journal of Positive Psychology, 10(2), 141-152.

Schueller, S. (2009). Promoting wellness: Integrating community and positive psychology. Journal of Community Psychology, 37(7), 922-937.

Seligman, M. E. P. (2011). Flourish. New York, NY: Free Press.

Seligman, M. E. P., \& Csikszentmihalyi, M. (2000). Positive psychology: An introduction. American Psychologist, 55, 5-14.

Shaughnessy, J. J., Zechmeister, E. B., \& Zechmeister, J. S. (2014). Research methods in psychology (10th ed.). New York: McGraw-Hill.

Sheridan, S., \& Burt, J. (2009). Family centered positive psychology. In S. J. Lopez \& C. R. Snyder (Eds.), Oxford handbook of positive psychology (2nd ed., pp. 551560). Oxford, UK: Oxford University Press.

Shum, D., O'Gorman, J., Myors, B., \& Creed, P. (2013). Psychological testing and assessment (2nd ed.). Melbourne, VIC, AUS: Oxford University Press.

Slemp, G. R., Chin, T.-C., Kern, M. L., Siokou, C., Loton, D., Oades, L. G., ... Waters, L. (2017). Positive education in Australia: Practice, measurement, and future directions. In E. Frydenberg, A. J. Martin, \& R. J. Collie (Eds.), Social and emotional learning in Australia and the Asia Pacific (pp. 101-122). Australia: Springer.

Snyder, C. R., Harris, C., Anderson, J. R., Holleran, S. A., Irving, L. M., Sigmon, S. T., ... Harney, P. (1991). The will and the ways: Development and validation of an individual-differences measure of hope. Journal of Personality and Social Psychology, 60, 570-585.

Stevens, S., \& Jarden, A. (2019). The importance of child wellbeing. International Journal of Wellbeing, 9(4), I-IV. https://doi.org/10.5502/ijw.v9i4.1011.

The Children's Society. (2019). How happy are our children: Measuring children's wellbeing and exploring economic factors. https://www.childrenssociety.org.uk/sites/def ault/files/tcs/research_docs/12pp\%20Well-being\%20Report.pdf. 
The Glossary of Education Reform. (2015). Assessment. https://www.edglossary.org/ assessment/.

Waters, L. (2017). Visible wellbeing in schools: The powerful role of instructional leadership. Australian Educational Leader, 39(1), 6-10.

Waters, L. (2018). Visible wellbeing: A critical resource for leadership and learning in schools. Horizon, 8, 4-10.

Waters, L., \& Loton, D. (2019). SEARCH: A meta-framework and review of the field of positive education. International Journal of Applied Positive Psychology, 4(1-2), 1-46.

Waters, L., Sun, J., Aarch, A., \& Cotton, A. (2016). Positive education: Visible wellbeing and the five domains of positive functioning. In M. Slade., L. Oades., \& A. Jarden (Eds). Wellbeing, recovery and mental health (Chapter 13; pp. 235260). Cambridge University Press.

Waters, L., Sun, J., Rusk, R., Aarch, A., \& Cotton, A. (2017). Positive education: Visible wellbeing and the five domains of positive functioning. In M. Slade., L. Oades., \& A. Jarden (Eds)., Wellbeing, recovery and mental health (pp. 245-264). Cambridge: Cambridge University Press.

Wrzesniewski, A. (2014). Engage in job crafting. In J. Dutton \& G. Spreitzer (Eds.), How to be a positive leader: Insights from leading thinkers on positive organisations (pp. 65-76). San Francisco: Berrett-Koehler Publishers.

Open Access This chapter is licensed under the terms of the Creative Commons Attribution 4.0 International License (http://creativecommons.org/licenses/by/4.0/), which permits use, sharing, adaptation, distribution and reproduction in any medium or format, as long as you give appropriate credit to the original author(s) and the source, provide a link to the Creative Commons license and indicate if changes were made.

The images or other third party material in this chapter are included in the chapter's Creative Commons license, unless indicated otherwise in a credit line to the material. If material is not included in the chapter's Creative Commons license and your intended use is not permitted by statutory regulation or exceeds the permitted use, you will need to obtain permission directly from the copyright holder. 